\title{
EFFECT OF COLLECTION FREQUENCY, EXTENDER AND THAWING TEMPERATURE ON THE MOTILITY RECOVERY OF CRYOPRESERVED DROMEDARY CAMEL SPERMATOZOA
}

Bahrawy, K. A. ; E. E. El-Hassanein and S. A. Rateb

Animal and Poultry Physiology Dept., Animal and Poultry Production Division, Desert Res. Center, 1 Mathaf El Mataryia Street, Cairo, Egypt

\begin{abstract}
The primary objective of this study was to examine ejaculate characteristics and quality of camel bull semen maintained under high ( 3 /week) and low ( 2 /week) collection frequencies during the breeding season. Ejaculate characteristics included motility, volume, concentration, detached acrosome, sperm abnormalities, pH, seminal plasma osmolarity and freezing point depression. Significant differences $(\mathrm{P}<0.01)$ were observed for ejaculate volume being $13.5 \mathrm{ml}$ versus $7.5 \mathrm{ml}$ for low and high collection frequency, respectively and also $\mathrm{pH}$ value $(\mathrm{P}<0.05)$ for low frequency of 8.7 versus 8.3 for high frequency semen collection.

The second objective was to determine the optimum thawing temperatures (slow thawing vs. rapid thawing) for cryopreserved camel semen extended in tris lactose extender supplemented with different concentrations of $\alpha$-amylase. Rapid thawing showed higher post-thaw motility for the control samples as well as the samples at different concentrations of the a-amylase treated samples. That leads to an overall significant difference $(P<0.01)$ in post-thaw motility for rapid thawing being $56.33 \%$ compared to $47.66 \%$ for slow thawed cryopreserved samples. No significant effect was detected for neither the detached acrosome percentage nor the sperm abnormalities.

According to the present results scheduling a collection program of two semen collection times per week, using alpha-amylase supplemented tris-lactose extender with rapid thawing protocol is recommended for a desired high yield of acceptable insemination doses during the breeding season of male camels.

Keywords: Dromedary, Semen, Collection frequency, Cryopreservation, Thawing
\end{abstract} rate.

\section{INTRODUCTION}

Efficient production of high quality semen of high genetic value is the most important aim of artificial insemination (Al) organizations. The improvement of quality and economics is limited by the number of insemination doses that can be obtained from one ejaculate and the number of appropriate quality ejaculates that can be obtained from a camel per week. For maximum reproductive efficiency, male bulls have to be managed that is to maintain normal sexual behavior and good libido. Allowing collection of high quality sperm using appropriate collection methods, intervals, and frequencies are very important aspects (Sieme et al., 2004).

El-Wishy (1987) assumed that the low productivity of camels is due to the low reproductive efficiency. Studying the reproductivety and modifying semen extenders and protocols for applying advanced reproductive 
technologies in family camelidea give high opportunities in improving its productivity (Al-Eknah,2000, Bravo, et al., 2000a, Aminu, et al., 2003, Khatir et al., 2006, Morton et al., 2006, Niasari-Naslaji, et al., 2006). Semen characteristics of alpacas were studied after repeated collections, (Bravo et al., 1997). In sum, frequency of mating affected some semen characteristics that may be important determinants of the fertility of male alpacas.

Successful semen storage is dependent on the reversible reduction in metabolic activity and motility, which prolongs the fertilizing lifespan of sperm (Evans and Maxwell 1987). This can be achieved by storing sperm in a liquid or frozen state. Cryopreservation of sperm in camelids is inefficient, primarily owing to lack of knowledge regarding camelid sperm physiology and the viscous nature of the seminal plasma (Bravo et al. 2000b). Camelid sperm are generally not tolerant to freezing and thawing procedures (Morton et al. 2009). At present the lack of efficient methods to preserve the fertilizing lifespan of semen in liquid or frozen form prevents the widespread use of Al in camelids. (Morton et al., 2009). Generally, the technical aspects of camel sperm cryopreservation have significantly improved over the last few decades. However, a standard protocol designed to optimize sperm motility recovery after thawing has not yet been established as well as, no data exists regarding characteristics of repetitively collected camel semen.

The primary objective of this investigation was to examine changes in ejaculate characteristics and semen quality over time in camels maintained under high and low collection frequencies. A secondary objective was to determine the effects of semen extender and freezing on semen quality under rapid and slow thawing conditions during the breeding season.

\section{MATERIALS AND METHODS}

Three healthy adult dromedary camel males (12 years old) with live average body weight of $500 \mathrm{~kg}$ were used in the present study for semen collection carried out in the artificial insemination laboratory in Maryout research station, Desert Research Center (DRC), located $34 \mathrm{~km}$ North West of Alexandria, Egypt.

Males were trained for semen collection by $42 \mathrm{~cm}$ artificial vagina (with a disposable plastic inner liner to avoid the expected lethal effect of rubber on sperm viability) filed with $40^{\circ} \mathrm{C}$ warmed water and placed in El-Hassanien camel dummy. With this system, a male may copulate for a time comparable to that of natural mating (approximately 25 to 30 minutes), semen samples are reliable, and the male's sexual behavior is not changed (El-Hassanien, 2003). Two semen collection regimes were done for two subsequent breeding seasons (twice a week vs. three times weekly). Collecting tubes with a modified plastic water jacket were used to maintain semen samples at $37^{\circ} \mathrm{C}$ during the long lasting collecting duration. Semen samples were transmitted immediately to a $37^{\circ} \mathrm{C}$ adjusted water bath for raw semen physical characters estimation. 


\section{Experiment 1:}

Physical semen characteristics:

The semen ejaculates were excluded if contaminated with urine, feces, strange substances, strange colour, odour or contains no sperms (azoosperrmia).

Semen volume: was assessed by graduated collecting glass tube.

Mass motility : Phase-contrast microscope (Leica), with warm stage at a power of $40 \mathrm{X}$ and an average of 5 fields was obtained to the nearest $5 \%$. For assessing seminal plasma

pH : Digital Cole-parmar pH meter was used with a micro probe indicator. Abnormalities and intact acrosome were determined according to Johnson et al. (1976), sample of $10 \mu \mathrm{l}$ semen was added to $200 \mu \mathrm{l}$ of a solution of $0.2 \%$ glutraldhyde using a phase - contrast microscope at $800 \mathrm{X}$.

Concentration: Diluted semen samples were counted with a heamocytometer counting slide taking in consideration the dilution factor. Osmolarity and freezing point depression (FPD): An Osmomat 030 apparatus was used for osmolarity estimation (Osmol/kg) , from which FPD was calculated by using the equation of Osmolarity (osmol/ $\mathrm{kg}) \mathrm{X}-1.858=(-$ ${ }^{0} \mathrm{C}$ ) Freezing Point Depression. (FPD). All parameters were determined according to El - Bhrawi (2005).

\section{Experiment 2:}

\section{Semen dilution, amylase enzyme supplementation and} cryopreservation:

A tris-lactose $3 \%$ glucerolated extender, supplemented with $20 \%$ fresh egg yolk and different concentrations of Supra-Terminal $\infty$-amylase enzyme with four different concentrations of $2.5,5,10,15 \mu \mathrm{l} / \mathrm{ml}$. were added to the previously prepared extender to eliminate seminal plasma viscosity inaddition to a control group free of alpha-amylase (El-Baharwy, 2010). Semen extension was carried out using a split sample technique in one-step freezing method on five different concentrations of a final dilution rate of 1 semen portion to 3 portions of extender.

Diluted semen was transported to a mini-tübe cooled handle cabinet for four hours equilibration time, before packing in $0.5 \mathrm{ml}$ French straws using a 133 model type mini-tübe filling and sealing machine. A $-140^{\circ} \mathrm{C}$ nitrogen vapor biological freezer (mini-tübe) was used for doses cryopreservation before transporting to the storage tanks for further post-thawing investigations.

\section{Thawing method:}

A programmable mini-tübe thawing device was used for slow and rapid thawing. The device was programmed for the desired time and temperatures which were $37^{\circ} \mathrm{C}$ for 40 seconds for slow thawing, while rapid thawing needed a higher temperature of $65^{\circ} \mathrm{C}$ for 10 seconds

\section{Statistical analysis:}

The results of raw semen statistical analysis were conducted using SAS ${ }^{8}$ (1988) software program. One way ANOVA of GLM procedure of SAS was used in each experiment. Extenders and thawing temperature data analysis were performed using SPSS software (SPSS version 11.5 for Windows; SPSS Inc., Chicago, IL, USA) computer program. Results are 
Bahrawy, K. A. et al.

quoted as arithmetic mean \pm standard error of mean (S.E.M.) and significance was attributed at $(p<0.01)$.

\section{RESULTS AND DISCUSSION}

\section{Experiment 1:}

The optimal ejaculation frequency is dependable on age, exercise and sexual potential. There is a natural ejaculation frequency that balances the testosterone level in the body. The effects of various frequencies of semen collection on several quantitative and qualitative semen characteristics were investigated in adult camels. Motility \%, volume, sperm cell concentration $/ \mathrm{ml}$. per ejaculate were determined for each ejaculate (Table 1).

The ejaculated volume of semen obtained with low frequency collection technique $(13.5 \mathrm{ml}$.) was higher than the ejaculates volume (7.3 $\mathrm{ml}$.) depending on high frequency rate $(P<0.01)$. Mathematically sperm cell concentration $/ \mathrm{ml}$. was also higher $454.61 \times 10^{6} \mathrm{vs} .310 \times 10^{6} \mathrm{sperm} / \mathrm{ml}$ for low and high collection frequencies, respectively, with no significant differences observed between groups. However, in the present experiment there were no significant differences between low and high frequencies for semen collection on motility percentage being 48.6 and $51.7 \%$, respectively, or for detached acrosome being $4.6 \%$ versus $6.2 \%$. Whereas, there were no significant differences for primary abnormalities percentage under the low and the high collection rates (5.3 versus $6.3 \%$ ), respectively. The same trend was observed for secondary abnormalities being $7.4 \%$ versus $9.5 \%$. No differences were also observed for osmolarity or for freezing point depression being 0.37 Osmol. $/ \mathrm{kg}$ and $-0.62{ }^{\circ} \mathrm{C}$ for low collection rate and $0.36 \mathrm{Osmol} . / \mathrm{kg}$ ,$-0.6^{0} \mathrm{C}$ for high collection rate, respectively.

Table (1): Effect of collection frequency on semen physical characteristics of male dromedary camels:

\begin{tabular}{|l|c|c|}
\hline \multirow{2}{*}{ Parameter } & Semen collection frequency per week (Mean \pm SE) \\
\cline { 2 - 3 } & $\begin{array}{c}\text { 2 collection days per } \\
\text { week }\end{array}$ & $\begin{array}{c}\text { 3 collection days per } \\
\text { week }\end{array}$ \\
\hline Mass motility (\%) & $48.6 \pm 3.3$ & $51.7 \pm 5.3$ \\
\hline Volume (ml.) & $13.5 \pm 1.46^{\mathbf{a}}$ & $7.3 \pm 1.01^{\mathbf{b}}$ \\
\hline Concentration X 10 ${ }^{6}$ sperm/ml. & $454.61 \pm 65.88$ & $310.73 \pm 43.97$ \\
\hline Detached acrosome (\%) & $4.6 \pm 0.83$ & $6.2 \pm 8.2$ \\
\hline First abnormalities (\%) & $5.3 \pm 0.31$ & $6.3 \pm 0.76$ \\
\hline Second abnormalities (\%) & $7.4 \pm 0.41$ & $9.5 \pm 1.41$ \\
\hline pH & $8.7 \pm 0.11^{\mathbf{a}}$ & $8.3 \pm 0.06^{\mathbf{b}}$ \\
\hline Osmolarity (Osmol./kg) & $0.370 \pm 0.01$ & $0.360 \pm 0.007$ \\
\hline Freezing pint depression $\left.{ }^{0} \mathrm{c}\right)$. & $0.620 \pm 0.21$ & $0.600 \pm 0.32$ \\
\hline
\end{tabular}

Different letters $a, b$ within the same rows indicates a significant difference $(\mathbf{P}<0.05)$

The present results confirm that decreasing the frequency of semen collection in camels partly increases semen yields per male, as increasing the frequency of semen collection had negative effects on ejaculate volumes without significantly affecting sperm cell concentrations. The relative 
advantages and disadvantages following high and low frequencies of semen collection have been previously demonstrated in different animal species (Bravo et al., 1997, alpacas; Sieme et al., 2004, stallions; Frangež et al., 2005, Boars; and Aguirre et al., 2007, rams).

The obtained results demonstrated a favorable effect of low semen collection frequencies on semen volume with no marked decline in other sperm characteristics. These results agree with those reported by Pickett et al., (1975) for stallions. A decrease in semen volume and sperm concentration with successive ejaculations has been reported in several studies on rams (Ollero et al.,1996; Kaya et al., 2002). We concluded that camel males express their optimal reproductive capacity more efficiently when semen collection is undertaken at a low rather than a high frequency. The frequency of semen collection in that species also influences the number of semen doses available for insemination having a higher yield of semen volume during the breeding season. That resulted in no significant difference for ejaculate characteristics taking in consideration higher non-significant mathematical value for sperm cell concentration. However, an explanation for the absence of significant differences in sperm concentrations between ejaculates from males subjected to collection at varying frequencies may be attributed to the relatively small number of males and to the high individual variability of semen parameters between males. Generally semen collection frequency has an impact on semen quality.

\section{Experiment 2:}

Table (2): Effect of different concentrations of $\alpha$-amylase on physical characteristics of camel semen under different thawing conditions:

\begin{tabular}{|l|c|c|c|c|c|c|c|c|}
\hline \multirow{3}{*}{ Thawing } & \multicolumn{5}{|c|}{ Slow } & \multicolumn{5}{c|}{ Rapid } \\
\cline { 2 - 9 } & \multicolumn{9}{|c|}{ Semen characteristics } \\
\cline { 2 - 9 } Treatment & Mot. \% & IA \% & $\mathbf{1}^{\text {st }}$ ab.\% & $\mathbf{2}^{\text {nd }}$ ab. \% & Mot.\% & IA \% & $\mathbf{1}^{\text {st }}$ ab.\% & $\mathbf{2}^{\text {nd }}$ ab.\% \\
\hline \multirow{2}{*}{ Control } & $40^{\mathbf{b}}$ & 7.0 & 10.3 & 9.6 & 46.6 & 9.6 & 6.67 & 7.6 \\
& \pm 2.8 & \pm 2.1 & \pm 2.6 & \pm 3.5 & \pm 9.2 & \pm 0.66 & \pm 0.33 & \pm 0.3 \\
\hline \multirow{2}{*}{$2.5 \mu \mathrm{l} / \mathrm{ml}$} & $40^{\mathbf{b}}$ & 12.3 & 10.6 & 10.6 & 53.3 & 10.3 & 7.0 & 8.3 \\
& \pm 2.8 & \pm 1.3 & \pm 0.3 & \pm 1.3 & \pm 10.9 & \pm 0.67 & \pm 1.15 & \pm 0.67 \\
\hline \multirow{2}{*}{$5 \mu \mathrm{l} / \mathrm{ml}$} & $55^{\mathbf{a}}$ & 9.67 & 9.6 & 14.0 & 58.3 & 11.0 & 5.3 & 6.3 \\
& \pm 0.01 & \pm 2.6 & \pm 1.2 & \pm 1.7 & \pm 8.3 & \pm 0.1 & \pm 0.88 & \pm 0.85 \\
\hline \multirow{2}{*}{$10 \mu \mathrm{l} / \mathrm{ml}$} & $56.6^{\mathbf{a}}$ & 12.6 & 10.0 & 8.6 & 56.6 & 10.6 & 8.0 & 9.0 \\
& \pm 4.4 & \pm 2.08 & \pm 1.15 & \pm 0.3 & \pm 4.4 & \pm 1.85 & \pm 1.0 & \pm 2.3 \\
\hline \multirow{2}{*}{$15 \mu \mathrm{l} / \mathrm{ml}$} & $55^{\mathbf{a}}$ & 10.0 & 8.66 & 9.3 & 61.6 & 10.4 & 5.0 & 7.0 \\
& \pm 5.7 & \pm 3.8 & \pm 1.2 & \pm 1.4 & \pm 4.6 & \pm 2.4 & \pm 1.57 & \pm 1.0 \\
\hline
\end{tabular}

a,b Means with different superscripts in the same column are significantly different at $P<0.05$

Mot. = Motility, IA = Intacted acrosome, $1^{\text {st }}$ ab. = Primary abnormalities, $2^{\text {nd }}$ ab. = Secondary abnormalities

The mean values obtained from semen physical parameters under different thawing rates are presented in (Table 2). Significant increase was obtained for sperm motility under different concentrations of amylase. The 
results showed that addition of $5,10,15 \mu \mathrm{l} / \mathrm{ml}$ of alpha-amylase had a significant positive effect in increasing the motility \% of semen samples postthawed under rapid and slow protocols being higher for rapid thawing (Table 2). No significant differences were detected between $2.5 \mu \mathrm{l} / \mathrm{ml}$ concentration and the amylase free extender (the control) as they both showed a significant decrease in motility percentages in the slow thawing procedure. On the other hand, rapid thawing protocol enhanced post thaw sperm motility under all treatments of alpha-amylase as well as the control group. Neither different amylase concentrations nor the thawing procedures had any significant effect on acrosomal reaction or abnormality of the post-thawed sperms, leading to no expected effect of both treatments on fertility.

The overall effect of rapid and slow thawing of the cryopreserved doses (Table 3) showed a significant effect $(P<0.01)$ in enhancing the post thaw motility with $56.33 \%$ for rapid thawing versus $47.66 \%$ for slow thawing. The same trend was monitored for a highly significant decrease $(P<0.01)$ on $1^{\text {st }}$ and $2^{\text {nd }}$ abnormalities with an approximate decrease of $30 \%$ under rapid thawing conditions, while no effect was detected on acrosomal integrity.

Table (3): Overall effect of rapid and slow thawing on cryopreserved semen dose:

\begin{tabular}{|l|c|c|c|c|}
\hline $\begin{array}{c}\text { Parameter } \\
\text { Treatment }\end{array}$ & Mot. \% & IA \% & $\mathbf{1}^{\text {st }}$ ab. \% & $\mathbf{2}^{\text {nd }}$ ab. \% \\
\hline Slow thaw. & $47.66^{\mathbf{b}} \pm 2.67$ & $10.33 \pm 1.03$ & $9.86^{\mathbf{a}} \pm 0.59$ & $10.46^{\mathbf{a}} \pm 0.89$ \\
\hline Rapid thaw. & $56.33^{\mathbf{a}} \pm 3.02$ & $10.46 \pm 0.57$ & $6.40^{\mathbf{b}} \pm 0.43$ & $7.67^{\mathbf{b}} \pm 0.53$ \\
\hline
\end{tabular}

a,b Means with different superscripts in the same column are significantly different at $P<0.01$

Mot. = Motility, IA = Intacted acrosome, $1^{\text {st }} \mathrm{ab}$. = Primary abnormalities, $2^{\text {nd }} a b$. = Secondary abnormalities

Motility is commonly believed to be one of the most important characteristics associated with the fertilizing ability of sperm. Significant differences had been observed in motility parameters between sperm that achieved a high percentage of fertilization and those that failed in the achievement of pregnancy (Donnelly et al., 1998 and Paulenz, et al., 2007). Thawing frozen sperm rapidly, apparently caused less membrane damage on thawing resulting in enhanced post-thaw motility and viability and reduced premature capacitation detected in primary abnormalities. This was confirmed in different animal species. Bradford \& Buhr (2002) on stallion reported that the fast thaw rate significantly increased the percent of progressively motile sperm compared with the slow and moderate thaw rates. The fast thaw rate also improved sperm viability. Dong, et al., (2009), on monkey also noticed that post-thaw motility was significantly lower in samples that were thawed slowly than those that were thawed rapidly. Warm water thaw exposes sperm to critically dangerous temperatures for only a brief time. The rise in temperature should be rapid enough to minimize sperm damage. A major criticism and concern for the warm water thaw is the danger of cold shock caused by mishandling of the straw following thaw. Cold shock is the permanent injury to sperm caused by a sudden decrease in semen temperature after thawing. Damage can result if the chosen thawing rate is 
inappropriate, as slow thawing results in re-crystallization of microcrystals of intracellular water and resulted damage to cellular organelles (Hammerstedt et al, 1990). The same observations were remarked by Zhang, et al., 1990, on stallion spermatozoa, while, Cumming, (1995) failed to prove these results in a study on bulls. As a generalization, the more rapid the cooling (freezing) rate, the more rapid should be the warming (thawing) rate. The ideal cooling and warming rates are also influenced by the composition of the extender. The process of thawing for insemination is potentially the most damaging to sperm due to rapid changes in volume.

\section{CONCLUSION}

It can be concluded that varying the frequency of semen collection in male camels, extender constituents and thawing temperature not only increases or impairs the quantities of spermatozoa available for insemination, but also modifies the initial rate of sperm viability in post-thawed semen. At a strategic level, the practical use of adequate frequencies of semen collections, coupled with the more investigations for semen processing and insemination protocols should provide useful tools for optimizing the fertilizing potential of the best camel sires in commercial situations

\section{Acknowledgment}

This study was gratefully supported by the Agriculture Research Developing Fund (ARDF). The authors thank Mr. Ibrahim El Hariery for his assistance in the laboratory work. Special acknowledgement is due to Mr. Demian Galy for his technical assistance during this work.

\section{REFERENCES}

Aguirre V, Orihuela A, Vázquez R. (2007). Effect of semen collection frequency on seasonal variation in sexual behaviour, testosterone, testicular size and semen characteristics of tropical hair rams (Ovis aries). Trop. Anim. Health Prod. ;39(4):271-7.

Al-Eknah MM. (2000). Reproductive in old world camels. Animal Reproduction Science, Vol. 60-61 (1-4): 583-592.

Aminu D, Vyas S and Sahani MS. (2003). Semen collection, cryopreservation and artificial insemination in the Dromedary camel. Animal Reprod. Sci. 77(223-233).

Bradford LL and Buhr MM. (2002). Function of cryopreserved horse semen is improved by optimized thawing rates. Journal of Equine Veterinary Science, Volume 22, Issue 12 , Pages 546-550.

Bravo PW, Ccallo M and Garnica J. (2000b). The effect of enzymes on semen viscosity in Llamas and Alpacas. Small Ruminant Research, Volume 38, Issue 1, Pages 91-95. 
Bravo PW, Flores D and Ordofiez C. (1997). Effect of repeated collection on semen characteristics of Alpacas. Biology of Reproduction, 57, 520524.

Bravo PW, Skidmore JA and Zhao XX. (2000a). Reproduction aspects and storage semen in Camelidae. Animal Reproduction Science 62, $173-193$.

Cumming IR. (1995). Suitability of the intact acrosome method for the prediction of fertility in bovine artificial insemination. Vet. Rec.; 25:28991.

Dong Q, Hill D and VandeVoort CA. (2009). Interactions among pre-cooling, cryoprotectant, cooling, and thawing for sperm cryopreservation in rhesus monkeys “ Cryobiology, Volume 59, Issue 3, Pages 268-274.

Donnelly ET, Lewis SEM, McNally JA, Thompson W. 1998. In vitro fertilization and pregnancy rates: the influence of sperm motility and morphology on IVF outcome. Fertil. Steril. 70(2):305-314.

El-Bahrawy KA. 2010. Cryopreservation of dromedary camel semen supplemented with a-Amylase enzyme. Journal of Camel Practice and Research. Vol. 17, No. 2, P. 211-216.

El - Bhrawi, K. A. (2005). Reproductive Studies on Desert Animals: Sexual Behaviour and Semen Characteristics and Freezability of Male Dromedary Camels. Ph.D. Thesis, Fac. Agric. Alex. Univ. Egypt.

El-Hassanien EE. (2003). An Invention for Easy Semen Collection from Dromedary Camels, El-Hassanien Camel Dummy. International Veterinary Information Service, Ithaca, New York, USA www.ivis.org/advances/Camel_Skidmore/hassanein/chapter_frm.asp ?

El-Wishy AB. (1987). Reproduction in the Female Dromedary (Camelus dromedarius). A Review. Anim. Reprod. Sci. 15.

Evans EBA and Maxwell WMC. (1987). Salamon's Insemination of Sheep and Goats Lecturer in Reproduction, Butterworths in Sydney, Boston..Pp. 194.

Frangež R, Gider T, Kosec M. (2005). Frequency of Boar Ejaculate Collection and its Influence on Semen Quality, Pregnancy Rate and Litter Size Acta Vet. Brno., 74: 265.

Hammerstedt RH, Graham JK and Nolan JP. (1990). Cryopreservation of mammalian sperm: what we ask them to survive. Journal of Andrology, Vol 11, Issue 1 73-88,

Johnson L, Berndtson WE and Bickett BW. (1976). An improved method for evaluating acrosomes of bovine spermatozoa. J. Anim. Sci. 42(4): 951-954.

Kaya A, Aksoy M, Tekeli T. (2002). Influence of ejaculation frequency on sperm characteristics, ionic composition and enzymatic activity of seminal plasma in rams. Small Ruminant Research, Vol.44, pp 153158.

Khatir H, Anouassi A, Tibary A. (2006). In vitro and in vivo developmental competence of dromedary (Camelus dromedarius) embryos produced in vitro using three systems of culture. First conference of the International Society of Camelids Research and Development (ISOCARD). April, 15-17. 
Morton KM, Gibb Z, Bertoldo M. and Chis Maxwell WM. (2009). Effect of diluent, dilution rate and storage temperature on longevity and functional integrity of liquid stored alpaca (Vicugna pacos) semen. Journal of Camelid Science 2, 15-25.

Morton KM, Ruckholdt M, Evans G and Maxwell WMC. (2006). Preliminary development of sperm sexing technology in alpacas (Lama pacos). First conference of the International Society of Camelids Research and Development (ISOCARD). April, 15-17.

Niasari-Naslaji A, Mosaferi S, Bahmani N, Gharahdaghi AA, Abarghani A, Ghanbari A and Gerami A. (2006). Effectiveness of a tris-based extender (SHOTOR diluent) for the preservation of Bactrian camel (Camelus bactrianus) semen. Cryobiology, Volume 53, Issue 1, Pages 12-21.

Ollero M, Muiño-Blanco T, López-Pérez MJ and Cebrián-Pérez JA. (1996). Viability of ram spermatozoa in relation to the abstinence period and successive ejaculations. International Journal of Andrology, Vol.19, pp. 287-92.

Paulenz H, Adnoy T and Soderquist L. (2007). Comparison of fertility results after vaginal insemination using different thawing procedures and packages for frozen ram semen. Acta Veterinaria Scandinavica, Vol.49, (Sep), pp. 0044-605X.

Pickett BW, Sullivan JJ, Seidel GE Jr (1975). Reproductive physiology of the stallion. V. Effect of frequency of ejaculation on seminal characteristics and spermatozoal output. J. Anim. Sci. 40(5):917-23.

SAS. (1988). SAS/STAT user's guide 6.03 edition. SAS Institute, Cary, North Carolina.

Sieme H, Katila T, Klug E. (2004). Effect of semen collection practices on sperm characteristics before and after storage and on fertility of stallions. Theriogenology, 61:769-784.

SPSS. (2006). Statistical Package for Social Sciences 15.0 for windows. SPSS Inc, USA.

Zhang J, Boyle MS, Smith CA, Moore HDM. (1990). Acrosome reaction of stallion spermatozoa evaluated with monoclonal antibody and zonafree hamster eggs. Mol. Reprod. Dev., 27:152-8. 
Bahrawy, K. A. et al.

تأثير معدل الجمـع والتخفيف و حرارة الاسـالة على استعادة الحركة فى سبرمات

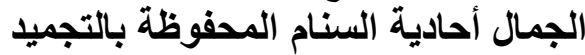

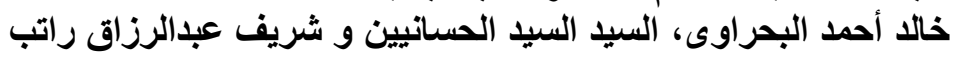
شعبة الانتاج الحيوانى - مركز بحوث الصدراء الصيد الصيبن و

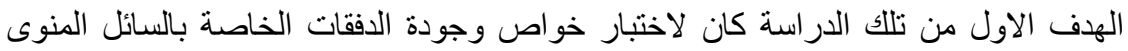

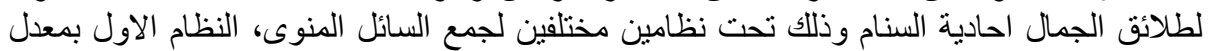

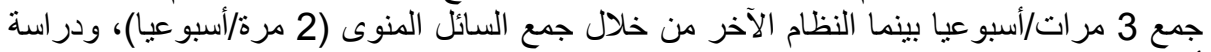

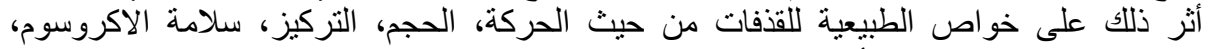

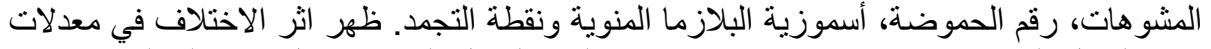

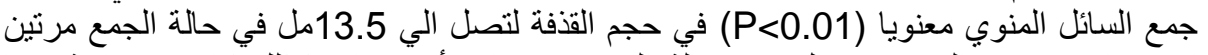

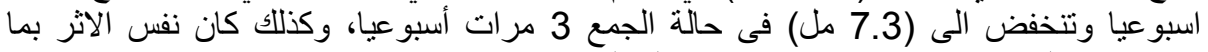

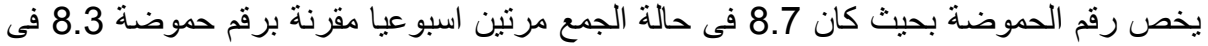

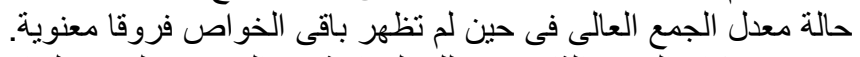

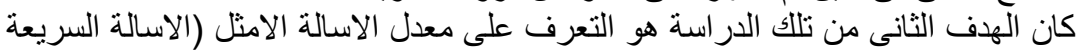

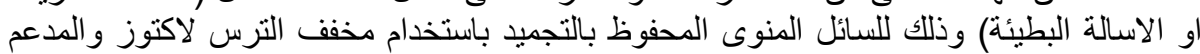

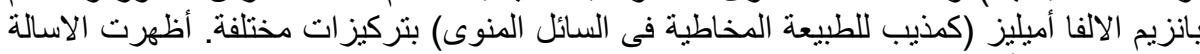

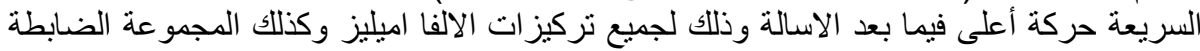

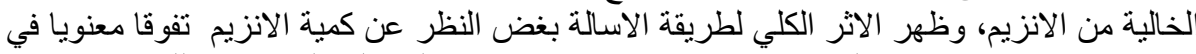

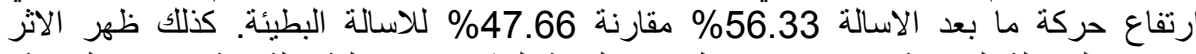

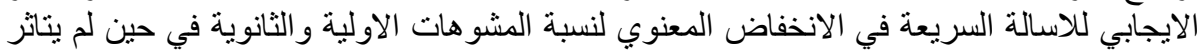

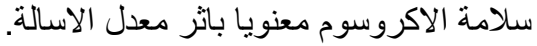

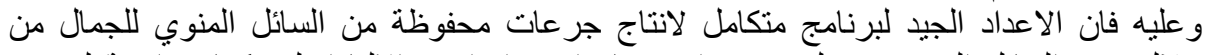

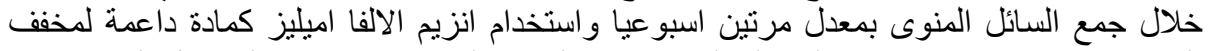

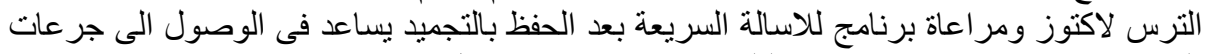
تلقيحية جيذة تساهم وتطوير برامج التلقيح الاصطناعى فى الابل.

كلية الزراعة - جامعة المنصورة

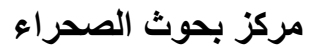

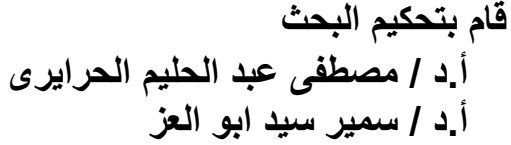

